\title{
Exploring societal participation in making cities smart
}

\author{
Shraddha Mahore Manjrekar ${ }^{1, *}$ and Manali Deshmukh, \\ 1 Brick School of Architecture, Pune (India) \\ 2 Brick School of Architecture, Pune (India)
}

\begin{abstract}
The word 'Future' has been synonymous to 'Development' for most of the people. Architects of the Nation strive for a well-developed state, where it reaches towards enhanced living conditions than the present. In this regard of development, structure of Indian government is well defined. The policies designed at central level envision the total development. These policies make the local bodies function on the same lines. They make an impression in common people's life that there are some positive changes in the cities. These policies also mark an identity, e.g., after implementation of city Development Plans under JNNURM (Jawaharlal Nehru, National Urban Renewal Mission), the buses bought for BRT (Bus Rapid Transport) had become identity of this policy. The meaning of Smart Cities in India also has been interpreted by people in many ways. For cities to become smarter it needs a holistic approach in developing a sustainable urban eco system and thus the roles of various stakeholders become very important in executing this mission. Not only the investors, financial organizations, planners, architects and people in construction industry but the citizens too have role in making cities smart. People of all age, gender, ability and disability are responsible in making a city smart. Education and awareness is the key for making them aware of their participation in the process of development. This paper also mentions the role of educational institutes to make people understand the essence of development.
\end{abstract}

Key words: Smart, Futuristic, Sustainable, Public participation, Education

\section{Introduction}

The objective of the Smart Cities Mission is to promote cities that provide core infrastructure and give a decent quality of life to its citizens, a clean and sustainable environment and application of 'Smart' Solutions. The local governance and various stakeholders are involved in this process. In line with the objectives of the mission, the project typology too has a common pattern in these cities. The categories of the works are, riverfront development projects, open spaces development, housing, App based projects for systemization of the administration, infrastructure and transportation etc. Dashboard of official website of the smart cities mission states that there are 100 winning proposal from various cities and estimation of 99,630,069 people getting affected by this mission [1]. The impact is also much visible in these respective cities. For example, Coimbatore city is working on desilting, bund strengthening, removal of weeds, turfing and lining, drains development, inter-linkages boating and water sports facilities, other amusement and recreational facilities, theme parks, medicinal gardens etc. Kochi city is working on upgradation of infrastructure in housing through credit linked schemes under the same mission. Pune city is working on intelligent government service for Bus System Intelligent Traffic Management System (ITMS), where the Smart Public is going to be equipped with Real time tracking of buses using GPS, maintenance using vehicle health monitoring system, Passenger Information System (PIS) with LED screens in buses and bus-stops and Mobile app to track -bus location and ETS real time, Ride quality monitoring using smart sensors, in -bus wifi and entertainment systems, etc. Digital India has reached till the limit where even a small vendor does digital transactions. Technologies have made the tasks easier. However, it cannot be said that the urban life has become easier with technologies. The complications, difficulties and the side effects of this technological up gradation have also been realized by people. Question that arises here is about total smartness, and its real perception in people.

\footnotetext{
*Corresponding author: iitrshraddha@gmail.com
} 
Smartness is not only about the superficial aesthetic quality or speed of works, but it is also about up gradation of civilization done together by people, places, things and systems. For example, the beautification of streets is a cosmetic surgery, as its going to add only into aesthetic part of it. ITMS, PIS, public screen may bring impression of technological up gradation but the convenient last mile connectivity of the mass rapid transport, and good quality of roads, pedestrian safety on these roads etc., will bring real smartness in the system.

This paper is based on a qualitative research, an attempt to identify and analyse of various parameters defining smartness with examples. It points out the gaps, between the policies and public participation. As a next step to this, the areas have been identified where people and education system can contribute to make their lives smarter. The role of education and educational institutes in conceiving the real essence of smartness has been elaborated in the further part of the paper.

\section{Defining smartness in urban context}

Smartness is both about the tangible and intangible aspects. Aesthetics of the city are important for cities to look smart, at the same time the functionality, efficiency and nearness to human values automatically represent smartness. A city can be smart with its people, places and systems. The various parameters defining smartness in the urban areas are:

- Efficient systems in place

- Intellectual smartness (people and system)

- Empathy for environment and people

- Value system for places and practices

- Futuristic, Sustainable and healthy

- Vibrant, Dynamic and Culturally alive

\subsection{Efficient systems in place}

The systems are of two types the administrative systems and infrastructural system. The urban local bodies and their functioning both have major role. Though there are similar systems of administration, however few cities have adopted some policies and set goals that have taken them till a level. Management of system with upgraded technologies and people's participation too have equal role in these systems.

For example, Indore city has been winner of 'Swachha Bharat Award' since three consecutive years (2016-19).
The major reason for its success is healthy competition between the wards. Every ward competes with each other in order to maintain their areas clean and beautiful. The efficient system of collection and transportation of garbage, processing and disposal of waste, clean sanitation (public toilets, proper drainage, etc.), people's participation and making people aware of cleanliness have worked well for Indore [2] (The Indian Express n.d.). City schools too have oriented the students to keep their surroundings cleaner.

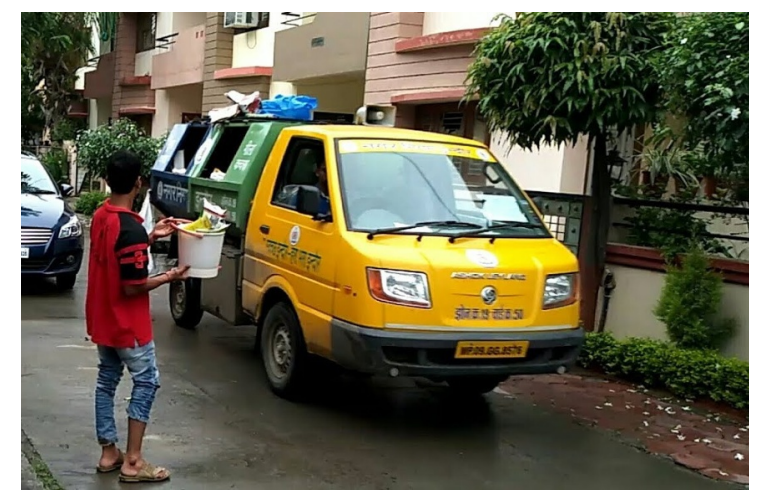

Fig. 1 A street in Indore city with its prototype waste collection system (India today 2019)

\subsection{Intellectual smartness (people and system)}

City is made with people. The knowledge, education and intellect of people to understand the surroundings is a must in executing the smart city mission. To develop these qualities, city's system should have infrastructure like educational institutes, libraries, laboratories, art schools, auditoriums, concert halls etc. For example, city of Oxford is known for its University, but other than that its identity is made also by theatres, concerts and other events. East oxford is the area with students' population and related infrastructure, press building, etc. The Plain, Cowley Road in East Oxford is the preferred place for trendy, both old and young, with a cinema, music venues, tattooists, and many good ethnic shops. West Oxford is full of a diverse landscape of waterways and islands (Oxford city n.d.)[3]. Figure 2 is a picture of a street in Oxford, showing prestigious institutional building, bicycle stand and people using bicycles.

People in oxford generally prefer walking and bicycling. They indulge in academics, arts, theatre, etc. Most of their activities are eco- friendly and add into character of the city. Hence other than buildings, streets and infrastructure, it is the people who have made an identity of the city. 


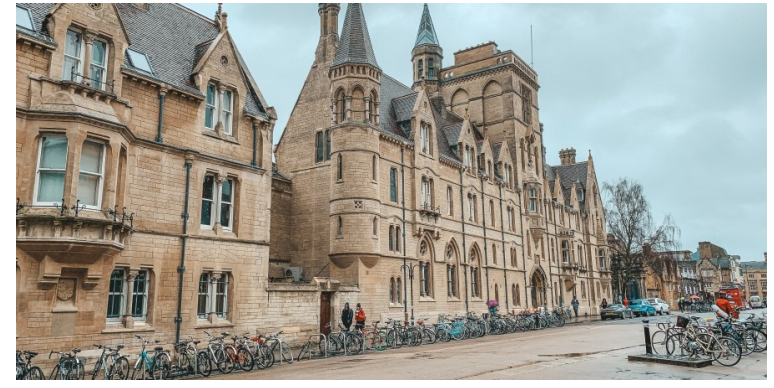

Fig. 2 A view of Oxford city (Source: UKtourcentre.com)

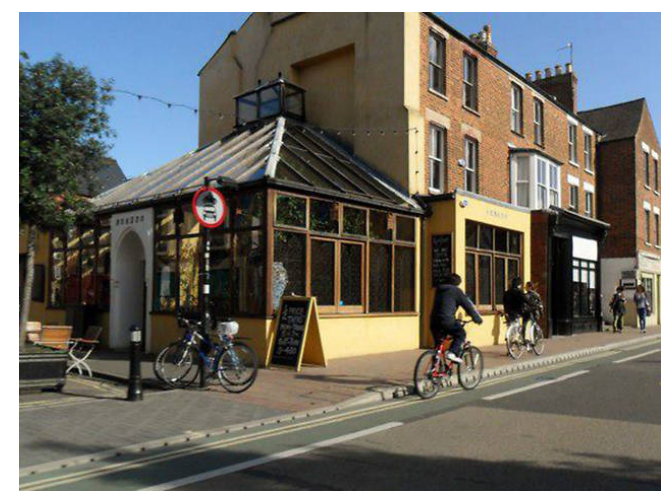

Fig. 3 Cowley Road, Oxford city (Source: UKtourcentre.com)

Ladakh, India is another example of smart citizens. Known by the name and works of Sonam Wangchuk, the area got its 'Education and cultural movement' for young kids in year 1988. Sonam Wangchuk ${ }^{\mathrm{a}}$ has come up with the uniquely systematic, collaborative \& community-driven reform of learning systems in remote Ladakh region. This system has helped to improve life opportunities for youths (Examrace n.d.)[4]. Education with strong application base has changed the picture of the area. Pune based activist Sarang Gosavi has also taken help of science and education to change people's lives in the same area. At one hand the area got good leadership by well qualified social reformer, and at the other hand it had been smart participation of local people to introduce better living conditions.

\subsection{Empathy for environment and people}

The developed state of civilization is sensitivity for humanity and environment. People should have value for fellow citizens and environment. Knowing about surroundings, owning, and taking care of it, makes area sustainable. Very good example here is of Central Park, New York City. New York City felt the need of a breathing place for people in year 1853. After city's joint

\footnotetext{
${ }^{a}$ Works of Sonam Wangchuk have been acknowledged by a Bollywood movie, "Three Idiots", in which Amir Khan has enacted Sonam in the character of Phunsukh Vangdu.
}

call, the New York State Legislature enacted into law the setting aside of more than 750 acres of land central to Manhattan Island to create America's first major landscaped public park [5] called Central Park (July 21, 1853). Since then there were several ups and downs in operation and maintenance of park, but the park sustained with people's efforts. (Central Park Conservancy n.d.) Today also with private public partnership the park is in good condition and visited by many people every day. The separate zones in this park are maintained by different groups of people. This zone management system has brought accountability, pride of workmanship, and clear and measurable results to the Conservancy and Parks Department staff.

Central park is an example of being sensitive about environment, however having sense of ownership to the surroundings has been culture of ancient India too. Sacred groves were actually the reserved forests and people regarded the trees and forests as almighty. Ironically, today in Indian cities, there are concrete walls around reserved forests to safeguard them from people. In the same lines, enforcement of 'Tree act' in Maharashtra state is a consequence of antienvironmental incidences in the past. At present there is Tree act, however there is a long way to sensitize people about total environment and ecology.

People are also part of environment; they have different abilities and disabilities, and city's ecosystem need to have respect for them and their convenience. Kautilya's Arthashstra has mention of city to have arrangements for looking after the aged, the children and informal people. Our built environment needs to be redesigned to meet the needs of physically challenged people. The vulnerability of the younger generation and senior citizens is more in present Indian cities, as they are not safe in terms of commuting on road because of heavy and unmanaged traffic and inappropriate road designs. Lessons need to be learnt from the cities that offer better living conditions to all. For example, in Singapore city, a six-year-old can alone commute in metro to go to school. Also, a senior citizen can commute anywhere in the city without any manual help. City's roads, public transport system, digitization of services support their easy life. At the same time, the people share these amenities, respect each other and give warm gestures while using these public amenities, and infrastructure. 


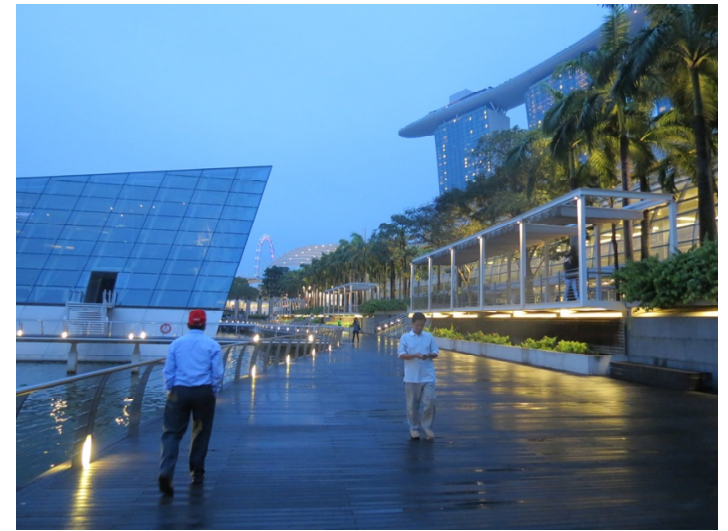

Fig. 4 Marina Bays, Singapore, an urban space having favourable commuting facilities for all

\subsection{Value system for places and practices}

Some places in the urban context have environmental, ecological or historical importance. Smartness of citizens includes having knowledge about these places, appreciating and valuing these. For example, Rome is a city of monumental buildings, monuments, sculptures and also of the ruins. The city administration and people have regarded and preserved the ruins equally like other historical undamaged buildings. The buildings and cityscape reflect the Christian culture and also history of war and victory over the enemies. A number of buildings in Rome have been built in memories of victories. After Second World War, the city grew in different fashion and had developed a vision to attract the world to appreciate the city through tourism. In order to make city ready for hosting international tourists, the new buildings have been built. However, it is noticeable to see that these newer buildings too have taken a distinct place in the harmony of entire city. Every new building has been built with due regard to its surrounding areas and the existing architecture. Figure 5 represents a picture from a Roman street where people have maintained the same façade to meet the street character.

Not only the construction but day to day activities too matter a lot in valuing the heritage component of the city. In Indian context there are old temples, residences, market places, open spaces, which need respect from daily commuters. The very first attempt is needed to make people aware about the context of the area. The heritage of the area is first respected by the locals than the tourists.

Indore city, India has demonstrated a good example of giving respect to historical monument, Holkar's Rajwada, by matching the façade character of the surrounding buildings with it. The uses of the surrounding buildings are different but they together make a market place with cultural identity.

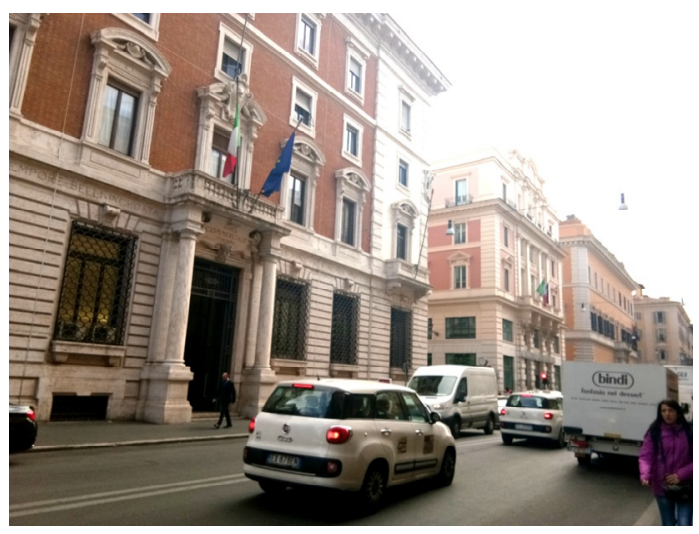

Fig. 5 A Street in Rome

\subsection{Futuristic, Sustainable and Healthy}

The historical places with good construction are still part of city and are lively, with their timeless character. The design of the spaces needs integrity that would be appreciated by future generations too. The resources are depleting, and the present time has complete liability to leave resources for the future. The design of buildings and urban spaces should be functional, aesthetically acceptable and at the same time energy and resources efficient. Climate is changing and dependency on mechanical means of comfort is increasing, however the building design has capacity to reduce the need of mechanical means of comfort. There are a number of Green buildings rating systems (LEED, GRIHA, EcoHousing, etc.) that give recognition to the sustainability of buildings; however, sustainability feature can be adopted as an accepted norm for being futuristic. Regarding urban spaces, too much dependency on mechanical means (lifts, motorized vehicles, etc.) has affected lifestyle and in turn it has degraded the public health. The cities need to be healthy. A simple example is pedestrian friendly roads with clean, and shaded walkways with lush green vegetation encourage people to walk, reduce fuel usage and keep the environment pollution free. Also, when people walk, they interact and the social life on streets is also seen. Pedestrian-priority street design is need of the hour, which is an urban public space with the highest priority for pedestrians and in some cases cyclists [6]. It has equivalent terminologies such as; a car-free street, a pedestrian zone, a pedestrian mall and a walk-able street (Basil Kamel 2017)

City of Bogota the capital of Columbia has set an example in world by reducing motorized vehicles on streets. The initiative that changed city in many positive 
ways is called Cyclovia that began in year 1974. Though implemented much later in year 1982, it is a success story. They started with a car free day event. Later when walking had become popular, people have accepted changed cityscape with promoted systems of walking and bicycling. Cyclovia brought a lot of environmental, health, economic and social benefits. Also, the social interaction between individual was significant, that resulted in increased sense of place and equity among the different classes of public realm. [7] Also a lot of economic benefits are obtained due to program investments and medical cost savings (Yassin 2019).

\subsection{Vibrant, dynamic and culturally alive}

Vibrancy in the urban environment can be brought both by spaces and people. Space design has potential of bringing vibrancy in the environment. The urban fabric is formed with vistas between buildings, sky and land. The landscape naturally changes with season. The vegetation in the area attracts birds and butterflies. Urban spaces integrated with landscape design have vibrant character. Cities must have pause points, where people stop and experience this vibrancy of the urban environment. Urban design may include water fountains, changing building facades, light and sound show elements to make the urban environment more vibrant.

Indian culture has many festivals that make streets lively. Keeping culture alive adds value to vibrancy of the area. Festivals change cityscape by decorations, festive markets, processions, and dance and music. Figure 6 represents a procession during Ganesh festival in Pune city, India. During the festival people and activities make the city colorful and vibrant. Any area full with people of different age, gender and communities make city vibrant.

Law garden is a park in Ahmedabad, is another good example of vibrancy. The street gets converted into market space in the evening time, and hence it has different character at day time and in the evenings. In the evenings, its souvenir shops, visitors and shopkeepers wearing traditional Gujarati costumes add a lot of vibrancy in the space. In the same city, Manek Chowk is a good example of space dynamics. This dynamism happens with people and their activities. The area is fully crowded with eateries and people since the evening to late nights. Early morning people get cattle in this area to feed the fodder. After this all the spaces are cleaned by municipal workers and by 10:00 am the shopkeepers open their jewellery shops. A same space offers environment for different activities and is dynamic in nature. The changes are so different in nature that a new person cannot imagine the next use of the space.

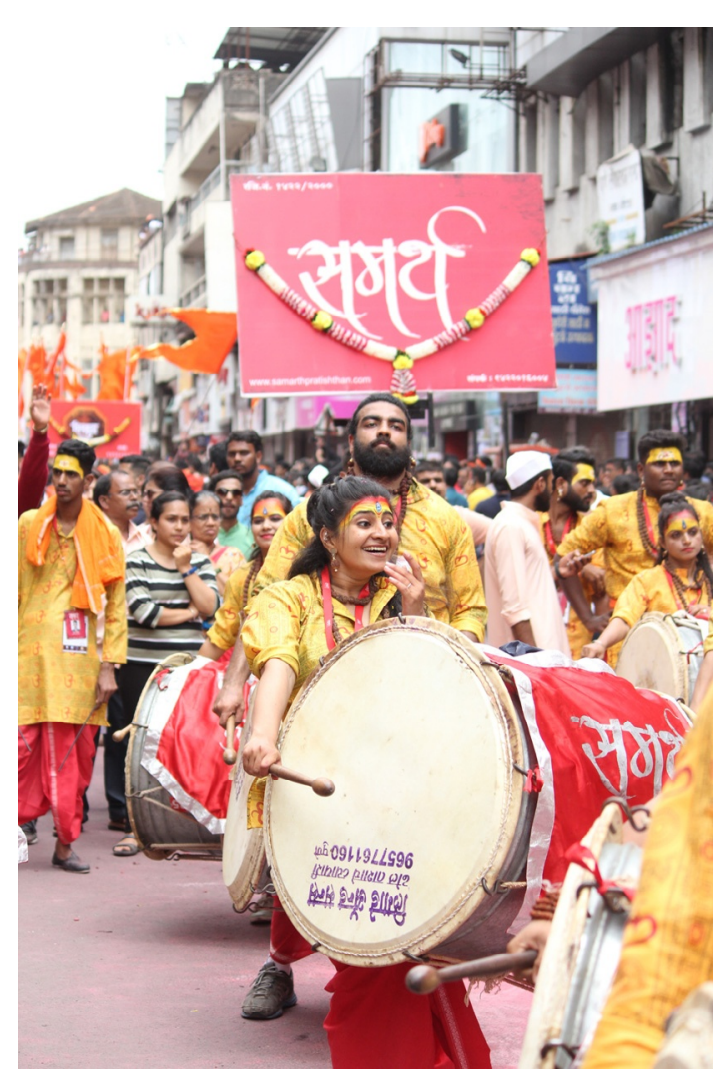

Fig. 6 Procession of Ganeshotsava, Pune

\section{Roles of various stakeholders in making cities smart}

India is a huge country and is known for its diverse topography and culture. Still the nation is united in many aspects. Indian government has remained successful in implementation of central policies with its efficient hierarchical system. The Niti Ayog, formerly 'Planning Commission' of India, has been working on a number of plans that have set language of translation at various stages. The administrative system of government is comprised of Central, State, Regional, District, and then respective local authorities. These function and title of these authorities depend on population, area and population density of the area (municipal council, municipal corporation, or Gram Panchayat). The census of the country done in every ten years is a detailed and systematic survey that conveys status of various socioeconomic, cultural and environmental status of the country. The central plans like five-year plans, ten year plans are result of the thoughtful process of National development based on these surveys.

For any mission of the central government there is healthy competition between the local authorities and at 
their level they work in the line with mission. For example JNNURM was a nationally accepted mission and local authorities were the most active role players in the same. Smart cities mission is also on the same lines.

However, for any governance to be successful in all regards, people's participation is must. Indian constitution has very well defined the roles and rights of the citizens. However, it has always remained a challenge to convey the responsibilities of the citizens. The perception of responsibility as a citizen is limited to giving vote to select the government, attending national festivals and paying tax on time. The other duties towards nation and environment are not so well defined, and hence peoples' contribution in making area smarter does not remain united. Every individual think about self-development but not for the area development. A general awareness about smart cities is also not evident, as people have noticed only the superficial component of the mission. As the previous part of paper conveyed the real essence of smartness, the next part of the paper highlights that how educational institutes play role in making area smarter with public participation.

\section{Contribution of Education and educational institutes to make cities smart}

Implementation of government policies aspiring to provide an enhanced infrastructure thus plays a vital role in the comprehensive development of a city. It can happen by involving organisations at a ward-level as a responsible instrument and will help in sensitizing the local people in respecting their neighbourhood and improving the urban eco-system. These organisations include educational institutes like secondary schools, undergraduate colleges, universities, and also non- profit organisations, government and semi government institutes in that ward. However, as the students constitute the majority of the population of any neighbourhood, it is best suited to involve the educational institutes in propagating the smart city mission and work towards the long-term goal of developing a sustainable urban eco -system.

Winner of the Magasasy award of year 2018, Engineer turned into Educationist Sonam Wangchuk says that the Education needs to be linked with life and should take into count the ground situation in different parts of India [8]. Various projects with an aim to respect their neighbourhood and improve the living environment can be included as part of their curriculum which addresses the responsibility of an individual to societal concerns. These points can be imparted in educational system.

\subsection{Traffic and transportation}

The areas near the periphery of the schools have a number of student and parents' commuters. In order to control the use of single occupancy cars, the commuting to school can act like a key. Institutes may formulate policies that govern commuting to schools/institutes by use of public transport, bicycles or walking. The defined area around school can make an identity by demonstrating reduced use of private cars.

\subsection{Sensitization about heritage sites, and environment}

Knowledge of the area and valuing it can be imparted best in schools. The academic lessons conducted in the premises of these structures and projects that trigger their thinking. It can also help in relating it to the literature taught, thus generating a sense of ownership and pride about the location. Pune, India has been a place for organizations like Balbhavan where cultural sessions are conducted for social interaction between different age groups (elderly and toddlers). Such organization can play a vital role in Smart cities by involving people in awareness sessions. This can remain instrumental in up keeping and regarding the heritage of the area.

Schools and institutions can promote activities to make people aware about the bio-diversity, natural resources and their role to respect and preserve it. The field trips and outdoor teaching can include these topics. At the same technical and professional education institutes can orient their pedagogy for area development through technological support. As an application of advancement in technology in the advanced sustainable infrastructure that needs to be incorporated. Projects dealing with smart solutions with emphasis given to energy and resource management can help in sustainable infrastructure and maintaining a better living environment. The development of technologies developed- robotics, sensory equipments to support this mission can encourage.

\subsection{Ownership of public spaces}

Urban spaces include parks and amenity areas. These spaces have major role in health and happiness quotient of the area. Areas could involve activities related to toddlers and elderly at the grass root level, e.g. Nana- 
Nani Park concept of Maharashtra, India. This is a concept of parks that has an intention of playful and caring interaction between elderly and toddlers. It gives a platform of learning and sharing of cultural intellect as well as newer versions of systems. This could help instil a sense of ownership and pride in respecting the culture along with the basic need of state of play for both the elderly and young. International Play Association (IPA) has wisely identified 'play' as right of every individual and an activity that improvises health and intellect. Giving priority to play can happen only when the urban areas and spaces support the safe and playful activities. IPA is approaching schools and neighbourhoods for this mission. Such missions can be clubbed with smart cities mission to activate institutes' participation for area development.

\subsection{Festivals and Cultural events}

Culture and festivals bring vibrancy in urban environment. Institutes can be actively involved during festivals in maintaining the balance of the cultural events with urban systems. The traffic management, waste management are common concerns during festive times. The voluntary roles of the institutes in this may include, supporting the assigned government officials in traffic management, spreading awareness for eco-friendly practices, etc. Educators and students together can play major role to educate the people for eco-friendly celebration of all the festivals. These activities can be helpful in making students smart, active and realistic. For institutes and smart cities mission it can be a winwin situation in the process of educating and making cities smart.

\section{Findings and Discussions}

Educational institutes play a vital role in strengthening the gap between the strategic planning in making smart cities. The study opens up the thought process for the institutes on how they can contribute to the area in which they are located. The various parameters of defining smartness in this paper convey that smartness is also about being aware of responsibilities as an individual in urban system. Reiterating on democratic approach- 'city of the people', citizens need to actively participate and share the responsibility to make an area smart. Educational institute have strength to unite the people and their efforts in multiple ways. A win-win situation between the governance and educators is in educating the younger generation about the land, ecology, environment, health, heritage, culture and festivals and their roles in developing a sustainable model in implementing the smart city mission.

\section{References}

\section{NIUA, Ministry of Housing and Urban} Development, Smartnet.

https://smartnet.niua.org/smart-citiesnetwork (accessed October 17, 2019).

2. The Indian Express, https://indianexpress.com/article/india/ indore-indias-cleanest-city-swachhbharat-mission-5662774/(accessed October 17, 2019).

3. Oxford city, Oxford visitors Information. https://oxfordcity.co.uk/aboutoxford/east-oxford/ (accessed OCtober $18,2019)$.

4. Examrace, https://Www.examrace.com/CurrentAffairs/NEWS-Mumbai-PsychiatristBharat-Vatwani-Ladakhi-EducationReformer-Sonam-Wangchuk-WinMagsaysay.htm (accessed November 2018).

5. Central Park Conservancy, https://staging.centralparknyc.org/?ut m_expid=.7uMp4LtfRrmxBFWTxEhVoA. 1\&utm_referrer=.

6. Kamel B., Wahba S., Kandil A., Fadda N. ,"Reclaiming Streets as Public Spaces for People: Promoting Pedestrianization Schemes in Al-Shawarbi Commercial Street - Downtown Cairo." SSRN Elecronic Journal, (January 2017).

7. Yassin, Hend H, "Livable city: An approach to pedestrianization." Alexandria Engineering Journal,

8. India times, 'Here's What India Needs To Do To Improve Its Education System By Sonam Wangchuk'(Aug 2018) 
9. India today, Swachha Bharat. June 2019.

https://Www.indiatoday.in/mail-

today/story/swachh-bharat-delhi-

narendra-modi-mcd-june-5-world-

environment-day-980517-2017-06-02

(accessed October 18, 2019). 